\title{
Assessment of the body response to specific fatigue exercise protocol SAFT90 in U16 soccer players
}

\author{
Barbora Sládečková*, Michal Botek, Jakub Krejčí, and Michal Lehnert \\ Faculty of Physical Culture, Palacký University Olomouc, Olomouc, Czech Republic
}

Copyright: (C) 2019 B. Sládečková et al. This is an open access article licensed under the Creative Commons Attribution License (https://creativecommons.org/licenses/by/4.0/).

Background: SAFT90 is a specific multidirectional fatigue protocol that imitates the internal and external load of soccer match-play. Objective: The aim of the study was to evaluate the impact of SAFT90 on lactate production, heart rate (HR) and rate of subjective perceived exertion (RPE) expressed by Borg scale (6-20). Methods: Fourteen male elite junior soccer players (age $15.9 \pm 0.2$ years, stature $180.8 \pm 5.5 \mathrm{~cm}$, body mass $69.8 \pm 5.8 \mathrm{~kg}$, body fat $8.1 \pm 3.2 \%, \mathrm{VO}_{2} \max 57.6 \pm 4.7 \mathrm{ml} \cdot \mathrm{kg}^{-1} \cdot \mathrm{min}^{-1}$, maximum heart rate $192.8 \pm 4.6$ beats $\cdot \mathrm{min}^{-1}$ ) participated in this study. Lactate concentration, HR and RPE were monitored during specific fatigue exercise protocol SAFT90. Results: Results of HR showed mean values of $153 \pm 15$ beats $\cdot \mathrm{min}^{-1}$, mean blood lactate concentration was $1.9 \pm 0.5$ $\mathrm{mmol} \cdot \mathrm{L}^{-1}$. A mean value of RPE was $11.0 \pm 1.4$ that corresponds to "fairly light" exercise. No significant change was found between consecutive SAFT90 stages for HR and lactate concentration. For Borg scale, there were significant increases between stages $20 \mathrm{~min}$ and $45 \mathrm{~min}$ and between stages $70 \mathrm{~min}$ and $90 \mathrm{~min}$. Change between stages 45 and 70 min was not significant. Conclusions: In respect to study results, we suggest that specific fatigue protocol SAFT90 applied in U16 soccer players appears to be insufficient in terms of exercise intensity to achieve comparable lactate concentration, HR and RPE values with a soccer match.

Keywords: exercise field-testing, external and internal load, lactate, heart rate, rate of perceived exertion, soccer performance

\section{Introduction}

Soccer as the most popular game in the world is played by men and women throughout all age categories and levels. During $90 \mathrm{~min}$ of a soccer match, adult players cover a distance of 10-12 km (Di Salvo et al., 2007). Previous studies have reported the distance $6-8 \mathrm{~km}$ in elite youth soccer players (U12-U16) while older players (U16) covered significantly higher total distances than U12 (Harley et al., 2010; Stølen, Chamari, Castagna, \& Wisløff, 2005). Game performance is characterized by alternating short intervals of high or low intensity. Intervals of high intensity are typically interspersed by passive or active recovery periods. During a soccer match, the level of heart rate (HR) is close to anaerobic threshold, usually $80-90 \%$ of maximal HR (Dellal et al., 2010; Stølen et al., 2005). Due to

\footnotetext{
* Address for correspondence: Barbora Sládečková, Department of Natural Sciences in Kinanthropology, Faculty of Physical Culture, Palacký University Olomouc, třída Míru 117, 771 11 Olomouc, Czech Republic. E-mail: sladeckova.b@seznam.cz
}

the duration, intermittent features and requirements of the game, aerobic capacity with emphasis on strength, speed and specific movement skills are considered important in terms of successful performance (Maly, Sugimoto, Izovska, Zahalka, \& Mala, 2018; Stølen et al., 2005). Although aerobic metabolism dominates, to perform crucial actions as jumps, short sprints, duel plays etc. require anaerobic energy release. A review of Stølen et al. (2005) involving both junior and senior soccer teams, reported the mean blood lactate concentration during a soccer match ranged between 2-10 $\mathrm{mmol} \cdot \mathrm{L}^{-1}$. However, Lehnert et al. (2018) presented post-test blood lactate concentration of $1.72 \pm 0.32$ $\mathrm{mmol} \cdot \mathrm{L}^{-1}$ and a moderate rate of perceived exertion (RPE). The previous findings showed higher blood lactate concentration in the first half of a soccer match (Bangsbo, 2007; Stølen et al., 2005). In male soccer $\mathrm{VO}_{2}$ max ranges from $50-75 \mathrm{ml} \cdot \mathrm{kg}^{-1} \cdot \mathrm{min}^{-1}$ according to age and playing position (Botek, Krejčí, McKune, \& Klimešová, 2016; Semjon, Botek, Svozil, \& McKune, 2016; Soyal, Korkmaz Eryllmaz, Polat, \& Aydoğan, 2017; Stølen et al., 2005). 
Another factor influencing soccer performance is somatic profile. Not only body height varies between soccer positions considerably, also body fat percentage varies from 7 to $12 \%$ among national senior soccer teams (Ademović, 2016; Reilly \& Williams, 2003). Semjon et al. (2016) reported that different playing positions require specific somatic characteristics. The crucial elements of soccer performance are regularly tested to evaluate the physical performance or effectiveness of training programs (Dragijsky, Maly, Zahalka, Kunzmann, \& Hank, 2017; Svensson \& Drust, 2005). Exercise field tests such as Yo-Yo test, INTER test, single-sprint test, multi-sprint test or laboratory tests (e.g., maximal aerobic power) do not imitate the overall soccer performance and real soccer conditions (Aandstad \& Simon, 2013; Svensson \& Drust, 2005). SAFT90 was created according to time-motion data analysis of 2007 English Championship Level matches and it imitates internal and external load of match-play (Barett, Guard, \& Lovell, 2013; Small, McNaughton, Greig, \& Lovell, 2010). SAFT90 is a shuttle running agility course with an intermittent exercise demand. SAFT90 takes $90 \mathrm{~min}$ and players cover $10.78 \mathrm{~km}$, 1,350 changes in direction, and 1,269 changes of pace (Small et al., 2010). According to Small et al. (2010) the players performing SAFT90 cover $3.36 \mathrm{~km}$ by walking, $5.58 \mathrm{~km}$ by jogging, $1.50 \mathrm{~km}$ by striding, and $0.34 \mathrm{~km}$ by sprinting. There is still a lack of studies examining and comparing the physiological response of SAFT90 with data from real soccer matches. The main aim of this study was to assess the response of selected internal body load indicators such as lactate, HR, and RPE to SAFT90 exercise protocol in male youth soccer players.

\section{Methods}

\section{Participants}

Fourteen male elite junior soccer players (age $15.9 \pm 0.2$ years, stature $180.8 \pm 5.5 \mathrm{~cm}$, body mass $69.8 \pm 5.8 \mathrm{~kg}$, body fat $8.1 \pm 3.2 \% ; \mathrm{VO}_{2} \max 57.6 \pm 4.7$ $\mathrm{ml} \cdot \mathrm{kg}^{-1} \cdot \mathrm{min}^{-1}$, maximum heart rate $192.8 \pm 4.6$ beats $\cdot \min ^{-1}$ ) playing first Czech junior league, took part in the study. Prior to testing, all tested participants were informed about the testing procedures and the aim of the research. All participants were asked to complete a health questionnaire to reassure they are free of any health problems. The day before testing, participants were not exposed to any exhaustive activity. The research was conducted in accordance with the Declaration of Helsinki and was approved by the Ethics Committee of the Faculty of Physical Culture, Palacký University Olomouc. The participation in this research was voluntary and all participants were asked to submit the consent of the legal guardian and sign informed assent with the testing procedure.

\section{Anthropometrical measurement}

A week before the exercise protocol, the participants underwent anthropometric measurements. The anthropometrical data were determined using bioimpedance analysis (Tanita BC-418 MA, Tanita, Tokyo, Japan).

\section{Maximal running test}

In order to obtain $\mathrm{VO}_{2}$ max and maximum heart rate (HRmax), all participants underwent maximal running test on treadmill (Lode Valiant, Lode, Groningen, Netherlands). The maximal running test was performed a week before the exercise protocol.

\section{Exercise protocol}

Immediately before $90 \mathrm{~min}$ of SAFT90 exercise protocol the participants completed 15 min warm-up. SAFT90 included a $20 \mathrm{~m}$ long course consisted of four positioned navigation poles. The exercise protocol consisted of following locomotion activities, standing, walking, jogging, running and sprinting. The intensity and activity during the test were directed by a CD player. The SAFT90 was divided into two 45 min halftimes with 15 min passive rest after the first half-time. All monitored parameters were recorded prior the testing and in 20th, 45th, 70th minute of the protocol (excluding 15 min rest time) and immediately after the end of the protocol. The protocol was performed outdoors on concrete pitch at the air temperature of $20-22{ }^{\circ} \mathrm{C}$.

\section{Heart rate monitoring}

HR was measured in periods of $5 \mathrm{~s}$ by Polar HR monitor RS800 (Polar, Kempele, Finland). All participants wore watches and chest straps. After the testing, the HR data were imported into the Polar ProTrainer 5 (Polar, Kempele, Finland) software. HR values at predetermined times were exported using the software.

\section{Blood lactate sampling}

Blood lactate level was determined using Lactate Scout+ analyser (EKF Diagnostics, Cardiff, United Kingdom). Capillary blood samples were taken from fingertip. Before each sample, the finger was cleaned in order to make the area clean and free of sweat. The skin was punctured using lancet and the first blood drop was wiped away, while the second drop was analyzed.

\section{Rate of perceived exertion}

At predetermined times the participants were asked to rate their perceived level of exertion using scale 
developed by Borg (Borg, 1982). All participants were familiarized with the Borg scale before the testing. The scale ranged from 6 (no exertion at all) to 20 (maximum exertion). The degree of subjective exertion was expressed both in numbers and in verbal terms on A4 paper. RPE was scored immediately after the end of the protocol.

\section{Statistical analysis}

Data are expressed as the mean $\pm S D$. An analysis of variance (ANOVA) for repeated measures was used to evaluate changes in the SAFT90 stages including the baseline level. When the omnibus effect of time was significant, Fisher's LSD post-hoc test was performed to evaluate changes between consecutive SAFT90 stages. A planned contrast with weights $(-4,1,1,1,1)$ was created to evaluate change between the baseline value and pooled mean of all SAFT90 stages. For all tests, the statistical level was set at $\alpha=.05$.

The effect size was calculated as Cohen's $d$. The following threshold values for effect size were adopted (Hopkins, Marshall, Batterham, \& Hanin, 2009): $<0.2$ (trivial), $\geq 0.2$ (small), $\geq 0.6$ (moderate), $\geq 1.2$ (large), $\geq 2.0$ (very large), and $\geq 4.0$ (extremely large). Statistical analysis was performed using STATISTICA (Version 12.0; StatSoft, Tulsa,
OK, USA) and MATLAB (Version 8.4; MathWorks, Natick, MA, USA).

\section{Results}

Means and $S D$ s of HR, lactate concentration, and Borg scale at baseline and during SAFT90 stages are depicted in Table 1 and showed in Figure 1. Statistical significances and effect sizes of changes between baseline and SAFT90 stages are provided in Table 1. HR during SAFT90 stages was $153 \pm 15$ beats $\cdot \mathrm{min}^{-1}$, $79.4 \pm 8.3 \%$ of HRmax.

The pooled mean of all SAFT90 stages was significantly increased compared to the baseline value for all studied variables, namely HR, lactate concentration, and the Borg scale. The effect size was extremely large for HR and very large for Borg scale, while for lactate concentration was only small. No significant change was found between consecutive SAFT90 stages for HR and lactate concentration and effect sizes were trivial or small. For the Borg scale, there were significant increases between stages $20 \mathrm{~min}$ and $45 \mathrm{~min}$ and between stages 70 min and 90 min with moderate effect sizes. Change between stages 45 and $70 \mathrm{~min}$ was not significant with trivial effect size.

Table 1

Results of statistical analysis of heart rate, lactate concentration, and Borg scale at baseline and during SAFT90 stages

\begin{tabular}{|c|c|c|c|c|c|}
\hline Variable/stage & Mean $\pm S D$ & $\Delta \pm 95 \% \mathrm{CI}$ & $p$ & $d$ & Effect size \\
\hline \multicolumn{6}{|c|}{ Heart rate (beats $\cdot \min ^{-1}$ ) } \\
\hline Baseline & $93 \pm 6$ & $59 \pm 8^{\mathrm{a}}$ & $<.001^{\mathrm{a}}$ & $4.39^{\mathrm{a}}$ & Extremely large \\
\hline $20 \mathrm{~min}$ & $154 \pm 14$ & & & & \\
\hline $45 \mathrm{~min}$ & $155 \pm 15$ & $1 \pm 5^{\mathrm{b}}$ & $.615^{\mathrm{b}}$ & $0.10^{\mathrm{b}}$ & Trivial \\
\hline $70 \mathrm{~min}$ & $150 \pm 14$ & $-5 \pm 5^{\mathrm{b}}$ & $.057^{\mathrm{b}}$ & $-0.38^{\mathrm{b}}$ & Small \\
\hline $90 \mathrm{~min}$ & $152 \pm 16$ & $2 \pm 5^{\mathrm{b}}$ & $.459^{\mathrm{b}}$ & $0.15^{\mathrm{b}}$ & Trivial \\
\hline \multicolumn{6}{|c|}{ Lactate concentration $\left(\mathrm{mmol} \cdot \mathrm{L}^{-1}\right)$} \\
\hline Baseline & $1.6 \pm 0.2$ & $0.2 \pm 0.2^{\mathrm{a}}$ & $.043^{\mathrm{a}}$ & $0.29^{\mathrm{a}}$ & Small \\
\hline $20 \mathrm{~min}$ & $2.1 \pm 1.1$ & & & & \\
\hline $45 \mathrm{~min}$ & $1.7 \pm 0.6$ & $-0.4 \pm 0.6^{\mathrm{b}}$ & $.149^{\mathrm{b}}$ & $-0.53^{b}$ & Small \\
\hline $70 \mathrm{~min}$ & $1.8 \pm 1.1$ & $0.1 \pm 0.6^{\mathrm{b}}$ & $.821^{\mathrm{b}}$ & $0.08^{\mathrm{b}}$ & Trivial \\
\hline $90 \mathrm{~min}$ & $1.8 \pm 0.5$ & $0.0 \pm 0.6^{\mathrm{b}}$ & $.900^{\mathrm{b}}$ & $-0.05^{b}$ & Trivial \\
\hline \multicolumn{6}{|l|}{ Borg scale } \\
\hline Baseline & $6.4 \pm 0.5$ & $4.6 \pm 0.8^{\mathrm{a}}$ & $<.001^{\mathrm{a}}$ & $3.08^{\mathrm{a}}$ & Very large \\
\hline $20 \mathrm{~min}$ & $10.1 \pm 1.7$ & & & & \\
\hline $45 \mathrm{~min}$ & $11.1 \pm 1.2$ & $1.0 \pm 0.8^{\mathrm{b}}$ & $.014^{\mathrm{b}}$ & $0.66^{\mathrm{b}}$ & Moderate \\
\hline $70 \mathrm{~min}$ & $10.9 \pm 1.9$ & $-0.1 \pm 0.8^{b}$ & $.717^{\mathrm{b}}$ & $-0.09^{b}$ & Trivial \\
\hline $90 \mathrm{~min}$ & $11.9 \pm 1.7$ & $1.0 \pm 0.8^{\mathrm{b}}$ & $.014^{\mathrm{b}}$ & $0.66^{\mathrm{b}}$ & Moderate \\
\hline
\end{tabular}

Note. $\quad \Delta=$ difference between the baseline value and the pooled mean of all SAFT90 stages $\left({ }^{\text {a }}\right)$ or difference between this stage and the preceding stage $\left({ }^{b}\right)$; CI = confidence interval; $p=$ significance of contrast $\left({ }^{a}\right)$ or significance of Fisher's LSD post-hoc test $\left({ }^{b}\right) ; d=$ Cohen's effect size; ${ }^{a}$ comparing the baseline value and the pooled mean of all SAFT90 stages; ${ }^{b}$ comparing this stage with the preceding stage. 

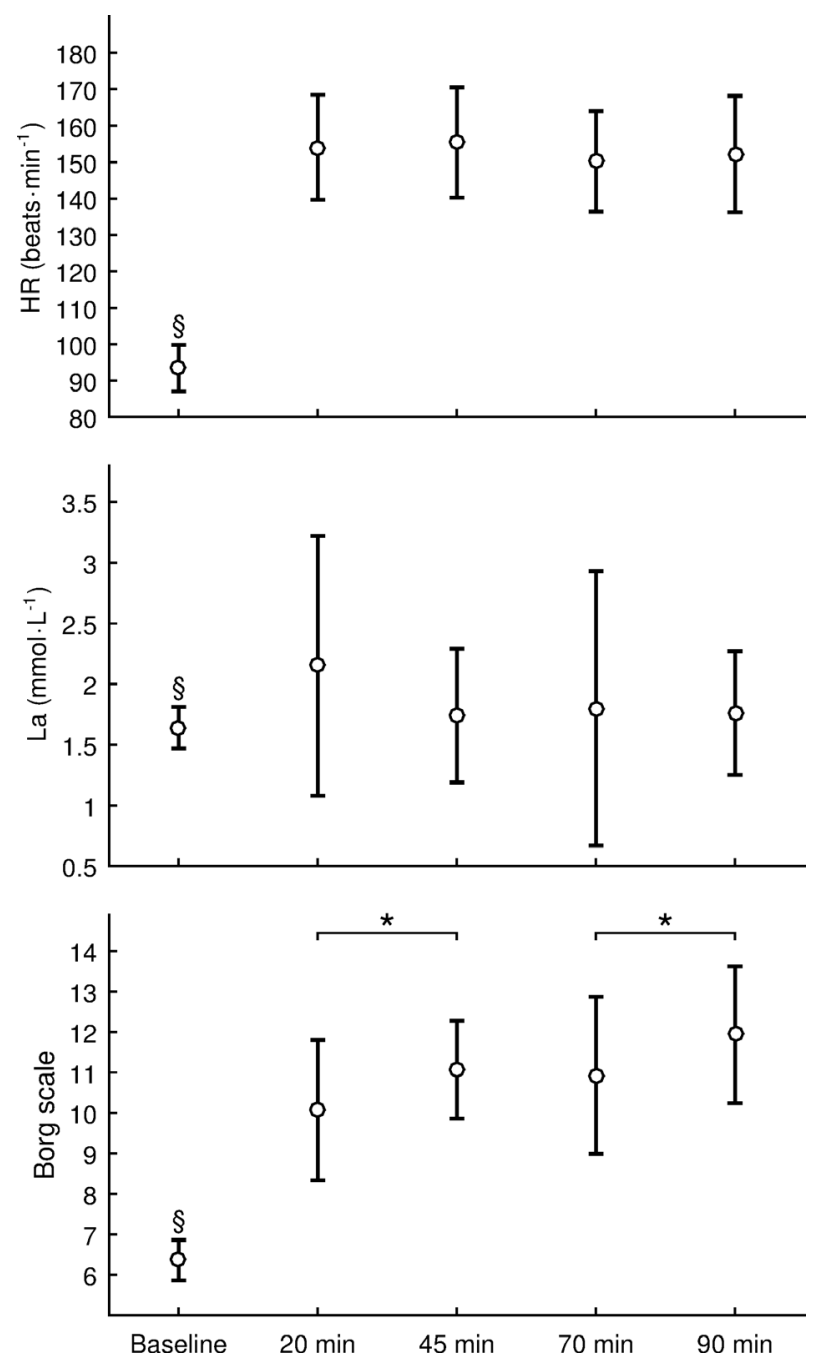

Figure 1. Means and $S D$ s of heart rate (HR), lactate concentration (La), and Borg scale at baseline and during SAFT90 stages. *significant difference between two means ( $p<.05$, Fisher's LSD post-hoc test); ${ }^{\S}$ significant contrast comparing the baseline value and the pooled mean of all SAFT90 stages $(p<.05)$.

\section{Discussion}

The aim of this study was to assess the body response to the standardized fatigue protocol SAFT90 in U16 soccer players. The main findings of this study revealed lower values in HR, lactate production and RPE when compared to common values observed in youth soccer players during the match play.

Lactate is the final metabolite product of anaerobic carbohydrates breakdown (Brooks, Fahey, \& Baldwin, 2004) that plays important role in high-intensity actions in soccer play such as repeated sprints (Stølen et al., 2005). An increased blood lactate concentration is associated with the elevated $\mathrm{H}^{+}$ions that decrease $\mathrm{pH}$ and consequently inhibit both ATP production, and muscle contractions (Brooks et al., 2004). One of the factors influencing lactate clearance is $\mathrm{VO}_{2} \max$ that plays an important role in recovery and aerobic performance (Tomlin \& Wenger, 2001). In male soccer players, $\mathrm{VO}_{2}$ max may range from $50-75 \mathrm{ml} \cdot \mathrm{kg}^{-1} \cdot \mathrm{min}^{-1}$ according to age and playing position (Semjon et al., 2016, Soyal et al., 2017; Stølen et al., 2005). Signoreli, Perim, Santos, and Araujo (2012) found young soccer players (17-22 years old) having $\mathrm{VO}_{2}$ max of $62.7 \pm 6.1$ $\mathrm{ml} \cdot \mathrm{kg}^{-1} \cdot \mathrm{min}^{-1}$. Comparable values reported Tønnessen, Hem, Leirstein, Haugen, and Seiler (2013) in their two decades study of professional soccer players in Norway. Due to the fact that $\mathrm{VO}_{2} \max$ is age-related, we need to highlight that the data for the creation of SAFT90 was collected from matches of adult soccer players while we tested U16 players. Botek et al. (2016) reported relatively stable $\mathrm{VO}_{2} \max \left(\sim 59 \mathrm{ml} \cdot \mathrm{kg}^{-1} \cdot \mathrm{min}^{-1}\right.$ ) in professional soccer players up to 30 years of age. It then decreases by $\sim 5 \%\left(\sim 3 \mathrm{ml} \cdot \mathrm{kg}^{-1} \cdot \mathrm{min}^{-1}\right)$ in the following nine years possibly due to a gain in body weight.

In our study, we found a significant increase in lactate concentration in 20th minute of the testing protocol compare to baseline. In the following samplingtimes we found a non-significant decrease. An average blood lactate concentration in the second part of the SAFT protocol was found at $1.8 \pm 0.7 \mathrm{mmol} \cdot \mathrm{L}^{-1}$ while $\mathrm{VO}_{2} \max$ of our participants was $57.6 \pm 4.7$ $\mathrm{ml} \cdot \mathrm{kg}^{-1} \cdot \mathrm{min}^{-1}$. Small (2008) previously found lactate values of $4.7 \mathrm{mmol} \cdot \mathrm{L}^{-1}$ and of $4 \mathrm{mmol} \cdot \mathrm{L}^{-1}$ after the first half and the second half of the SAFT90 in semi-professional soccer players at the age of $22 \pm 4$ years, and equal $\mathrm{VO}_{2}$ max to our study $(57.6 \pm 5.1$ $\left.\mathrm{ml} \cdot \mathrm{kg}^{-1} \cdot \mathrm{min}^{-1}\right)$. Due to the same $\mathrm{VO}_{2} \max$ values to our study, we suggest that higher lactate concentration might be explained by anthropometric characteristics of the players. The anthropometrics differences related to age in soccer players are discussed later in this manuscript. The higher lactate values reported by Small (2008) are comparable to lactate values assessed during soccer match by Russell, Benton, and Kingsley (2014) who reported values of $5.0 \pm 0.7 \mathrm{mmol} \cdot \mathrm{L}^{-1}$ in the final $15 \mathrm{~min}$ of the match in ten British male soccer players (age $15.6 \pm 0.2$ years, $\mathrm{VO}_{2} \max 58.4 \pm 0.8$ $\left.\mathrm{ml} \cdot \mathrm{kg}^{-1} \cdot \mathrm{min}^{-1}\right)$. Lactate ranging from 3.24 to 4.62 $\mathrm{mmol} \cdot \mathrm{L}^{-1}$ found Aslan et al. (2012) who examined players $\left(\mathrm{VO}_{2} \max 51.76 \pm 4.18 \mathrm{ml} \cdot \mathrm{kg}^{-1} \cdot \mathrm{min}^{-1}\right)$ of different playing positions. In the review of Stølen et al. (2005) all included studies reported average blood lactate concentration after the second half of the matchplay ranged between 2.5 and $10 \mathrm{mmol} \cdot \mathrm{L}^{-1}$ in elite and $1^{\text {st }}$ division players throughout different age categories. Based on lactate concentrations and $\mathrm{VO}_{2} \max$ values reported in this part of our discussion we suggest that lower values of lactate production in the present study 
might be explained by insufficient applied exercise intensity. This suggestion is supported by HR values mentioned in the following paragraph.

HR has widely been used as an indicator of exercise intensity in many studies. This is based on the fact that there is a linear relationship between HR, work rate and oxygen consumption (Arts \& Kuipers, 1994). HR is a simple and available device to monitor exercise intensity. In the present study average HR during SAFT protocol was $153 \pm 15$ beats $\cdot \min ^{-1}(\sim 79 \%$ HRmax) while its dynamic was in accordance with the dynamic of lactate concentration. A significant increase in HR compared to baseline values was recorded in the 20th minute of SAFT90 and then a non-significant decrease was found during the rest of the testing protocol. The most previous studies dealing with soccer demonstrated values above $80 \%$ of HRmax (Capranica, Tessitore, Guidetti, \& Figura, 2001; Henderson, Cook, Kidgell, \& Gastin, 2015). Coelho et al. (2016) tested 44 players U17 and U20 who were monitored during 29 official soccer matches. The average values of all monitored participants ranged between $80 \%$ and $85 \%$ of HRmax in the first and the second half of the soccer match. Even higher values between $85 \%$ and $95 \%$ HRmax found Veale and Pearce (2009) and Aslan et al. (2012). Authors dealing with SAFT90 reported an average HRmax between $82.2 \%$ and $83.3 \%$ (Barrett et al., 2013; Small, 2008).

Whereas the data for SAFT90 were obtained from matches of adults (Small, McNaughton, Greig, \& Lovell, 2010), in the present study we tested youth soccer players. The lower values of both lactate concentrations and HR might be partly explained by different $\mathrm{VO}_{2} \max$ values and anthropometric characteristics of adults and junior soccer players. Anthropometrics characteristic particularly body mass, influence $\mathrm{VO}_{2}$ max. Botek et al. (2016) found the differences up to $10 \mathrm{~kg}$ between adults (20-39 years old) and youth (17-19.9 years old) professional soccer players. In the same study, authors found differences in the average percentage of body fat between $8.7 \%$ (17-19 years old) and $12.5 \%$ (30-39 years old). The lower (7\%) and homogenous values of fat content confirmed Arroyo, Gonzalez-de-Suso, Sanchez, Ansotegui, and Rocandio (2008). Also, Sever and Zorba (2017) showed considerable differences in body height and body mass between soccer players under 16 and over 17 years old. Body mass can play an important role in the change of direction, acceleration or deceleration.

RPE is an important indicator of an individual's degree of physical strain (Borg, 1982). It has been studied in many different kinds of exercises in both the laboratory and the field conditions as well as in many different groups of individuals, both healthy and diseased. Borg, Hassmén, and Lagerström (1987) and Zinoubi, Zbidi, Vandewalle, Chamari, and Driss (2018) found approximately linear increases in HR and RPE. The average rate of RPE in the present study was $11.0 \pm 1.4$. This value demonstrates a "fairly light" exercise. Although our results demonstrate significant increase in RPE at the 45th min compared to the 20th min, and the 90th min compared to the 70th min, based on previous results we suggest that elevated RPE values at the end of each half period might reflect more mental exertion (fatigue) because RPE changes were not followed by cardiovascular and/or metabolic response. The study of junior soccer players of Aslan et al. (2012) showed average RPE $11.48 \pm 1.28$ in the 1st half and $13.64 \pm 1.28$ in the 2 nd half of a match. However, these values correspond to "fairly light" and "somewhat hard" exercise.

Although it seems that SAFT90 does not stimulate metabolism enough, it has been shown that SAFT90 induces muscular changes and influence muscular performance (Jones, Ryan, \& Todd, 2015). Lehnert et al. $(2018,2017)$ did not found significant changes in muscular control however, they reported impaired absolute leg stiffness and relative leg stiffness after SAFT90.

One limitation of this study might be the lack of information about our participants' lactate, HR and RPE values from soccer match play. As well concrete surface used in the current study could affect current participants. Another limitation includes the lack of neuromuscular tests. We also suggest including control group and cross-sectional design for better indication of the results.

\section{Conclusions}

Taken together, both objective and subjective internal load indicators showed that values of SAFT90 for our male elite junior soccer players, did not represent exercise with sufficient intensity to cause required physiological and psychometric response. Hence, to replicate the fatigue response of soccer match play, we recommend for highly trained youth soccer players a fatigue protocol with a more demanding activity profile.

\section{Acknowledgments}

This study was supported by the Czech Science Foundation (grant number 16-13750S) and by the Internal Grant Agency of Palacký University Olomouc (grant number IGA_FTK_2019_002). 


\section{Conflict of interest}

There were no conflicts of interest.

\section{References}

Aandstad, A., \& Simon, E. V. (2013). Reliability and validity of the soccer specific INTER field test. Journal of Sports Sciences, 31, 1383-1392.

Ademović, A. (2016). Differences in the quantity and intensity of playing in elite soccer players of different position in the game. Homo Sporticus, 18(1), 26-31.

Arroyo, M., Gonzalez-de-Suso, J. M., Sanchez, C., Ansotegui, L., \& Rocandio, A. M. (2008). Body image and body composition: Comparisons of young male elite soccer players and controls. International Journal of Sport Nutrition and Exercise Metabolism, 18, 628-638.

Arts, F. J. P., \& Kuipers, H. (1994). The relation between power output, oxygen uptake and heart rate in male athletes. International Journal of Sports Medicine, 15, 228-231.

Aslan, A., Açıkada, C., Güvenç, A., Gören, H., Hazır, T., \& Özkara, A. (2012). Metabolic demands of match performance in young soccer players. Journal of Sports Science \& Medicine, 11, 170-179.

Bangsbo, J., Iaia, F. M., \& Krustrup, P. (2007). Metabolic response and fatigue in soccer. International Journal of Sports Physiology \& Performance, 2, 111-127.

Barrett, S., Guard, A., \& Lovell, R. J. (2013). Elite-youth and university-level versions of SAFT90 simulate the internal and external loads of competitive soccer. In H. Nunome, B. Drust, \& B. Dawson (Eds.), Science and football VII (pp. 95-100). Abingdon, United Kingdom: Routledge.

Borg, G. A. (1982). Psychophysical bases of perceived exertion. Medicine \& Science in Sports \& Exercise, 14, 377-381.

Borg, G., Hassmén, P., \& Lagerström, M. (1987). Perceived exertion related to heart rate and blood lactate during arm and leg exercise. European Journal of Applied Physiology \& Occupational Physiology, 56, 679-685.

Botek, M., Krejčí, J., McKune, A. J., \& Klimešová, I. (2016). Somatic, endurance performance and heart rate variability profiles of professional soccer players grouped according to age. Journal of Human Kinetics, 54, 65-74.

Brooks, G. A., Fahey, T. D., \& Baldwin, K. M. (2004). Exercise physiology: Human bioenergetics and its applications (4th ed.). London, United Kingdom: McGraw-Hill Education.

Capranica, L., Tessitore, A., Guidetti, L., \& Figura, F. (2001). Heart rate and match analysis in pre-pubescent soccer players. Journal of Sports Sciences, 19, 379-384.

Coelho, D. B., Coelho da Paixão, R., Cruz de Oliveira, E., Kappes Becker, L., Ferreira-Júnior, J. B., Gomes Coelho, L., \& Silami-Garcia, E. (2016). Exercise intensity during official soccer matches. Revista Brasileira de Cineantropometria \& Desempenho Humano, 18, 621-628.

Dellal, A., Keller, D., Carling, C., Chaouachi, A., Wong, D. P., \& Chamari, K. (2010). Physiologic effects of directional changes in intermittent exercise in soccer players. Journal of Strength and Conditioning Research, 24, 3219 -3226.

Di Salvo, V., Baron, R., Tschan, H., Montero, F. C., Bachl, N., \& Pigozzi, F. (2007). Performance characteristics according to playing position in elite soccer. International Journal of Sports Medicine, 28, 222-227.

Dragijsky, M., Maly, T., Zahalka, F., Kunzmann, E., \& Hank, M. (2017). Seasonal variation of agility, speed and endurance performance in young elite soccer players. Sports, 5 , 12.

Harley, J. A., Barnes, C. A., Portas, M., Lovell, R., Barrett, S., Paul, D., \& Weston, M. (2010). Motion analysis of match-play in elite U12 to U16 age-group soccer players. Journal of Sports Sciences, 28, 1391-1397.

Henderson, B., Cook, J., Kidgell, D. J., \& Gastin, P. B. (2015). Game and training load differences in elite junior Australian football. Journal of Sports Science \& Medicine, 14, 494-500.

Hopkins, W. G., Marshall, S. W., Batterham, A. M., \& Hanin, J. (2009). Progressive statistics for studies in sports medicine and exercise science. Medicine \& Science in Sports \& Exercise, 41, 3-13.

Jones, R. I., Ryan, B., \& Todd, A. I. (2015). Muscle fatigue induced by a soccer match-play simulation in amateur Black South African players. Journal of Sports Sciences, 33, 1305-1311.

Lehnert, M., De Ste Croix, M., Xaverova, Z., Botek, M., Varekova, R., Zaatar, A., ... Stastny, P. (2018). Changes in injury risk mechanisms after soccer-specific fatigue in male youth soccer players. Journal of Human Kinetics, 62, 33-42.

Lehnert, M., De Ste Croix, M., Zaatar, A., Hughes, J., Varekova, R., \& Lastovicka, O. (2017). Muscular and neuromuscular control following soccer-specific exercise in male youth: Changes in injury risk mechanisms. Scandinavian Journal of Medicine \& Science in Sports, 27, 975-982.

Maly, T., Sugimoto, D., Izovska, J., Zahalka, F., \& Mala, L. (2018). Effect of muscular strength, asymmetries and fatigue on kicking performance in soccer players. International Journal of Sports Medicine, 39(4), 297-303.

Reilly, T., \& Williams, A. M. (Eds.) (2003). Science and soccer (2nd ed.). London, United Kingdom: Routledge.

Russell, M., Benton, D., \& Kingsley, M. (2014). Carbohydrate ingestion before and during soccer match play and blood glucose and lactate concentrations. Journal of Athletic Training, 49, 447-453.

Semjon, M., Botek, M., Svozil, Z., \& McKune, A. J. (2016). Positional differences in the cardiorespiratory, autonomic, and somatic profiles of professional soccer players. Acta Gymnica, 46, 90-96.

Sever, O., \& Zorba, E. (2017). Investigation of physical fitness levels of soccer players according to position and age variables. Facta Universitatis: Series Physical Education \& Sport, 15, 295-307.

Signorelli, G. R., Perim, R. R., Santos, T. M., \& Araujo, C. G. (2012). A pre-season comparison of aerobic fitness and flexibility of younger and older professional soccer players. International Journal of Sports Medicine, 33, 867-872.

Small, K. A. (2008). Effect of fatigue on hamstring strain injury risk in soccer (Unpublished doctoral dissertation). University of Hull, Hull, United Kingdom.

Small, K., McNaughton, L., Greig, M., \& Lovell, R. (2010). The effects of multidirectional soccer-specific fatigue on markers of hamstring injury risk. Journal of Science and Medicine in Sport, 13, 120-125. 
Soyal, M., Korkmaz Eryılmaz, S., Polat, M., \& Aydoğan, S. (2017). Comparison of maximal oxygen uptake and anaerobic threshold in soccer and handball players. Physical Education of Students, 21, 171-175.

Stølen, T., Chamari, K., Castagna, C., \& Wisløff, U. (2005). Physiology of soccer: An update. Sports Medicine, 35, 501-536.

Svensson, M., \& Drust, B. (2005). Testing soccer players. Journal of Sports Sciences, 23, 601-618.

Tomlin, D. L., \& Wenger, H. A. (2001). The relationship between aerobic fitness and recovery from high intensity intermittent exercise. Sports Medicine, 31, 1-11.
Tønnessen, E., Hem, E., Leirstein, S., Haugen, T., \& Seiler, S. (2013). Maximal aerobic power characteristics of male professional soccer players, 1989-2012. International Journal of Sports Physiology and Performance, 8, 323-329.

Veale, J. P., \& Pearce, A. J. (2009). Physiological responses of elite junior Australian Rules footballers during matchplay. Journal of Sports Science \& Medicine, 8, 314-319.

Zinoubi, B., Zbidi, S., Vandewalle, H., Chamari, K., \& Driss, T. (2018). Relationships between rating of perceived exertion, heart rate and blood lactate during continuous and alternated-intensity cycling exercises. Biology of Sport, 35, 29-37. 